\title{
Powder and Solvent for Prolonged- Release Suspension for Injection Dosage Form
}

National Cancer Institute

\section{Source}

National Cancer Institute. Powder and Solvent for Prolonged-Release Suspension for Injection Dosage Form. NCI Thesaurus. Code C149791.

Sterile powder and sterile solvent intended for the preparation of a prolonged-release suspension for injection by dispersing the powder in the solvent. 